\title{
Converting Contour-Line Data into Data Sets for a Multilayered Aquifer Using a Geographic Information System
}

BY JULIE A.H. REES

Open-File Report 99-54 


\title{
U.S. DEPARTMENT OF THE INTERIOR BRUCE BABBITT, Secretary
}

\author{
U.S. GEOLOGICAL SURVEY
}

Charles G. Groat, Director

The use of firm, trade, and brand names in this report is for identification purposes only and does not constitute endorsement by the U.S. Geological Survey.

For additional information write to:

Copies of this report can be purchased from:

District Chief

U.S. Geological Survey

Water Resources Division

520 North Park Avenue, Suite 221

Tucson, AZ 85719-5035
U.S. Geological Survey Information Services

Box 25286

Federal Center

Denver, CO 80225-0046 


\section{CONTENTS}

Abstract

Introduction

Purpose and scope

Hydrogeology of the west Salt River Valley.....

General geographic information system data-conversion methods.

Line- and lattice-data preprocessing

Land-surface altitude

Basin-fill unit altitude contours

Creating and checking the surfaces

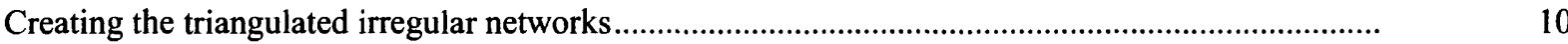

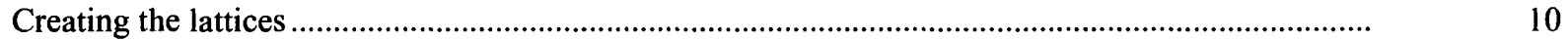

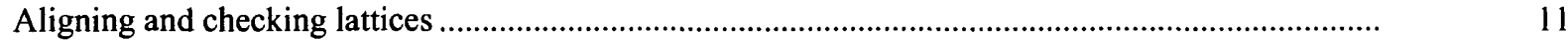

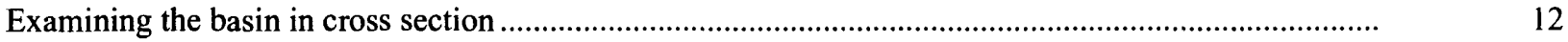

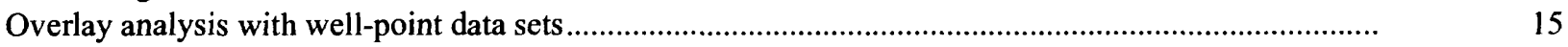

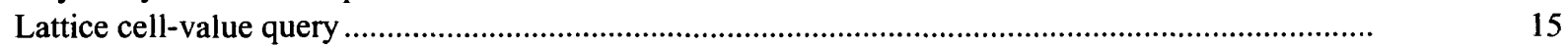

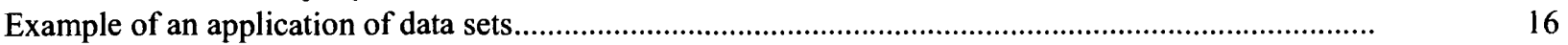

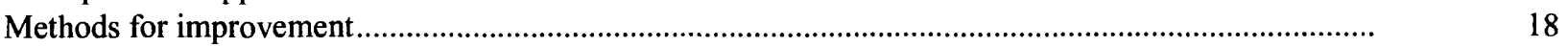

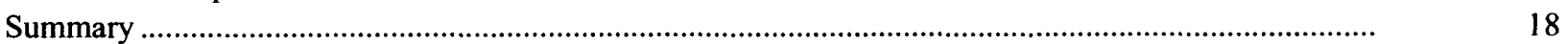

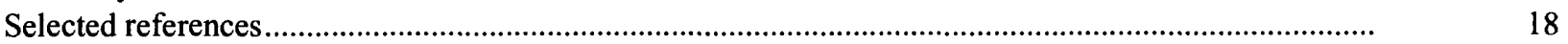

Supplemental data:

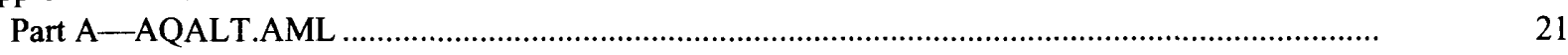

Part B - Example of an RDB file converted from output of AQALT.AML ..................................... 27

\section{FIGURES}

1. Map showing west Salt River Valley study area, which is part of the Central

Arizona Basins National Water-Quality Assessment (NAWQA) program in Arizona ............. 2

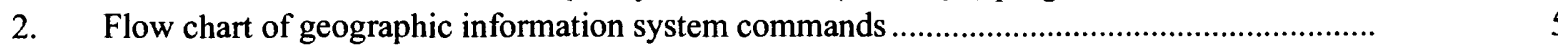

3-5. Maps showing:

3. Shaded land surface generated from digital elevation model (DEM) files of 1:250,000-scale maps used to define land surface before clipping to the extent of study area

4. Approximate lines of equal altitude of the bases of the basin-fill units, west Salt River Valley:

A. Base of the upper unit $\left(Q_{s}\right)$

B. Base of the middle unit $\left(Q_{T s}\right)$

C. Base of the upper part of the lower unit $\left(T_{s u}\right)$

5. Surfaces generated by triangulated irregular network (TIN) for the four basin-fill units in the west Salt River Valley:
A. Base of the upper unit $\left(Q_{s}\right)$
B. Base of the middle unit $\left(Q_{T s}\right)$
C. Base of the upper part of the lower unit $\left(T_{s u}\right)$
D. Base of the lower part of the lower unit $\left(T_{s l}\right)$. 
6. Map and cross section showing wells, land surface, and the bases of the upper and middle basin-fill units, and the base of the upper part of the lower unit.

\section{TABLES}

1. Descriptions and ranges in altitude of basin-fill units

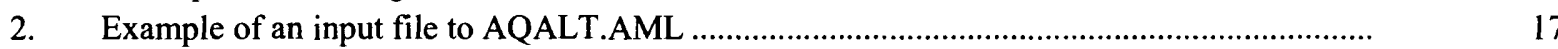

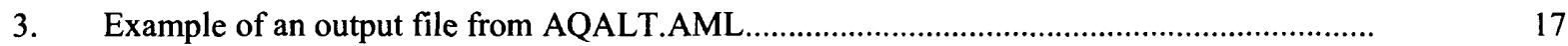

\section{CONVERSION FACTORS}

\begin{tabular}{rll}
\hline Multiply & By & To obtain \\
\hline meter $(\mathrm{m})$ & 3.281 & foot \\
kilometer $(\mathrm{km})$ & 0.6214 & mile \\
square kilometer $\left(\mathrm{km}^{2}\right)$ & 0.3861 & square mile \\
\hline
\end{tabular}

\section{VERTICAL DATUM}

Sea level: In this report, "sea level" refers to the National Geodetic Vertical Datum of 1929 (NGVD of 1929)-a geodetic datum derived from a general adjustment of the first-order level nets of the United States and Canada, formerly called Sea Level Datum of 1929. Altitude, as used in this report, refers to distance above or below sea level and is used in reference to the altitude values of the digital elevation model (DEM) files distributed by the U.S. Geological Survey as part of the National Mapping Program.

\section{DEFINITION OF TERMS}

Arc Macro Language (AML) - A post-processing scripting language for use with Arc/Info software.

Arc/Info-A geographic information system [GIS; Environmental Systems Research Institute (ESRI)], which includes the relational data-base manager, Info.

Attributes - Data related to a theme used by a spatial-data set, for example, a coverage. Also called an "item," or "item attribute." Attributes are saved in relational data-base tables called an arc attribute table (.AAT) or a polygon (or point) attribute table (.PAT).

Calc command-A command in Arc/Info, which allows for arithmetic calculations of attributes with numeric values.

Clip-A GIS process to confine the areal extent of a spatial-data set usually by defining the extent of one data set by the extent of another.

Clean coverage - A coverage with corrected topology and an attribute table-an .AAT or a .PAT.

Coverage-A data set within GIS composed of points, lines, or polygons. Data are stored in a rational data base in the form of a data table, which is comprised of attribute items and the corresponding data values. Point and polygon coverages have data stored in .PAT tables; line coverages have data stored in the .AAT tables. 
Data set-Information stored digitally on a computer in a relational data base. The GIS forms of thi ase data sets can be a coverage, triangulated irregular network (TIN), or lattice (also called a grid). Each coverage, TIN, or lattice contains data as item attributes within a relational data base.

Fuzzy tolerance-The "minimum distance separating all arc coordinates in a coverage." Fuzzy tolerance defines how much a line can move out of position as a result of many Arc/Info actions. Out-of-position movement can happen as a result of the "limited arithmetic precision of computers" (Environmental Systems Research Institute, 1996).

Geographic information system (GIS)-A system that is composed of spatial data and a relational data-base manager. The GIS data base stores spatial data by way of describing topology, which is the explicit definition of relations between objects.

Isolines - Lines of equal value on a map.

Lattice-A means to interpret irregularly spaced features. A lattice is more discrete, or steplike, than a TIN, and is composed of cells of a particular mesh size or resolution with one $z$ value for each cell. The lattice file has two components. One component is the header with information describing the origin, number of sample points, and the distance between sample points. The second component is a matrix of $z$ values. Coordinates of $x$ and $y$ values of each sample point are reconstructed from the origin and resolution information and are not stored.

Overlay - To relate the theme of one spatial-data set with the theme of other spatial-data sets. All data sets in an overlay operation are georeferenced.

Raster-Data that are cell based within a matrix; each cell has a specific value.

Script-A computer program.

Stackprofile command-An Arc/Info command to draw a profile for section lines over stacked surface-data sets, such as TIN's.

Triangulated irregular network (TIN)-A means to interpret irregularly spaced features, such as contour-line nodes or points, as a "three-dimensional" surface. Nodes are the points from the lines used to define the shape of the contour, each having $x, y$, and $z$ data. Edges connect the nodes and are used to calculate the slope between the nodes. Triangles define the facets of the surface, as they are composed of three nodes and their connecting edges, and therefore have information regarding spatial position and slope to the neighboring spatial point. All three measurements must be in the same unit of measure and have the same point of origin.

Weed tolerance- The minimum allowable distance between two vertices along an arc (Environmental Systems Resource Institute, 1996). (Arcs are defined by the placement of vertices similar to a "connect-the-dots" puzzle). The weed tolerance of one arc will not affect the vertices of a neighboring arc even if the neighboring arc is within the weed-tolerance distance. 


\title{
Converting Contour-Line Data into Data Sets for a Multilayered Aquifer Using a Geographic Information System
}

\author{
By Julie A.H. Rees
}

\section{Abstract}

Data sets that define the altitude of the base of basin-fill units in the west Salt Rive* Valley were developed for the National Water-Quality Assessment program using a geographic information system. Data that define the land surface and the base of each basin-fill unit within a multilayered aquifer were compiled into a series of raster-data lattices. The lattice of each basin-fill layer was constructed using contour lines from a published hydrogeologic reprrt. The land-surface lattice was constructed from 1:250,000-scale digital elevation models of the area. The resulting raster-data set was queried to define the altitude of the base of each basin-fill unit at specified locations. Using a computer script to be run within a geographic information system, a table was produced that provided information that related the altitude of the bottom of the wells to the altitudes of the bases of the basin-fill units. A comparison of the altitude at the bottom of wells with the range in altitude between each basin-fill unit base made it possible to begin to determine the basin-fill unit in which wells were completed.

\section{INTRODUCTION}

The Central Arizona Basins National WaterQuality Assessment (NAWQA) program was designed to develop a nationally consistent data base of the status and trends of current water-quality conditions for much of the Nation's water resources and to provide a scientifically sound understanding of the factors affecting water quality. The 60 study units of NAWQA collectively represent much of the Nation's major river basins and aquifer systems and include the study of surface-water and ground-water quality. The Central Arizona Basins (CAZB) study unit covers $89,870 \mathrm{~km}^{2}$ in central and southern Arizona, which includes $2,850 \mathrm{~km}^{2}$ in Mexico.

The west Salt River Valley (WSRV) is in the south-central part of the CAZB study unit near west Phoenix (fig. 1). Historically, the area has been used for agriculture such as growin? alfalfa and cotton and managing dairies and feedlots. Present-day urbanization of the area is stre ssing the water supplies, which are primarily grourd water. Streamflow is ephemeral except for areas of effluent and irrigation-return flow from west Phoenix, Glendale, Sun City, Buckeye, Avondale, and Goodyear (Brown and Pool, 1989). Natural flow from the major streams originates outside the basin. Overall, water is used primarily for crop irrigation and other agricultural uses; however, as the statewide population increases, the demand for good-quality drinking water will increase. Land used for agriculture could be a source of pasticides and other chemical constituents in ground water (Cordy, 1994).

As part of the CAZB study unit, a groundwater subunit survey of the WSRV subbasin was made to assess the water quality of major aquifers 


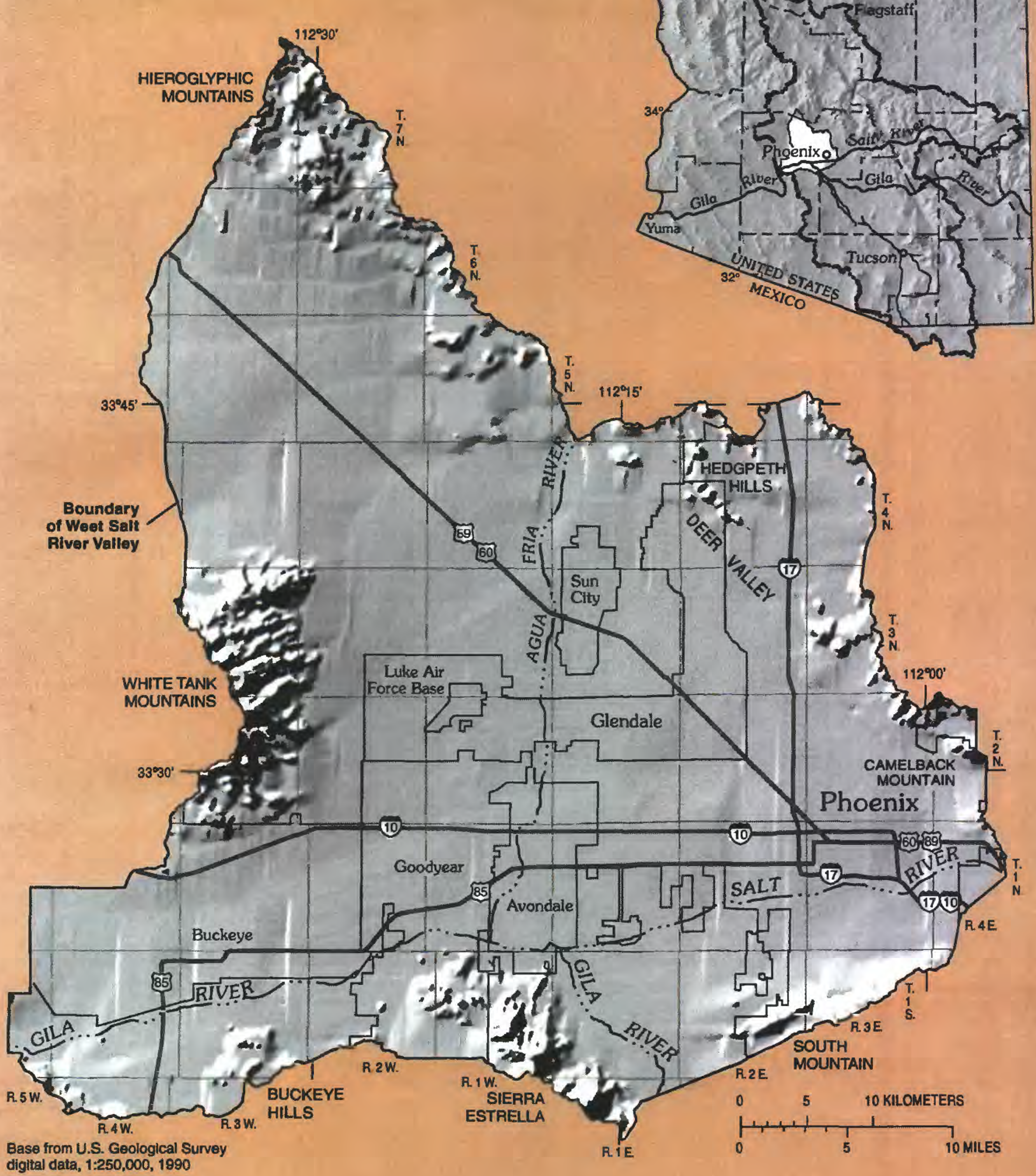

digital data, 1:250,000, 1990

Figure 1. West Salt River Valley study area, which is part of the Central Arizona Basins National Water-Quality Assessment (NAWQA) program in Arizona. 
by sampling and analyzing water from existing wells. During the survey, a need arose to determine the relations among depths of wells, depths of basin-fill units that compose the regional aquifer; water quality within each unit; and differences between units. To meet this need, a technique was developed to determine the unit in which selected wells were completed as a cursory look at retrospective data.

\section{Purpose and Scope}

The purpose of this report is to describe the geographic information system (GIS) techniques that were used to refine the definition of the bases of the upper and middle basin-fill units and the bases of the upper and lower parts of the lower basin-fill unit in the WSRV and to describe an example of how the data sets were used by applying overlay techniques. Hydrogeologic data from Brown and Pool (1989) were used in the preprocessing of the GIS data sets and the creation of the final relational data-base files.

\section{Hydrogeology of the West Salt River Valley}

The WSRV is a northwestward-trending, broad alluvial basin bounded by a series of mountains (fig. 1). According to Shafiquallah and others (1980), the mountains and subsurface bedrock are typically metamorphic or granitic rocks but may include some volcanic or sedimentary rocks. The basin fill consists of unconsolidated to semiconsolidated sediments contained by the surrounding impermeable bedrock. The basin fill dips toward the center of the basin where a large central graben was formed by block faulting 15 to 8 million years ago (Shafiqullah and others, 1980). Stream alluvium overlies the basin fill along the channels of the Salt, Gila, and Agua Fria Rivers.

According to Brown and Pool (1989), the aquifer in the WSRV is composed of three hydrogeologic units. Each hydrogeologic unit is distinguished from the others by particle size and hydraulic characteristics. The contacts between units often are difficult to determine because of gradual lithologic changes between the units, shared lithologic characteristics, and lack of data. Nonetheless, basic descriptions of each unit based on gravimeter, lithologic, and hydraulic data are described by Brown and Pool (1989; table 1, this report). In this report, GIS techniques were used to refine the contours defining three units from Brown and Pool (1989) into four surfaces of the basin fill the bases of the upper unit, the midfle unit, and the upper and lower parts of the lower unit.

The depth to bedrock, lithology, and thickness of the units vary between the northeas ${ }^{+}$rn and southwestern parts of the basin and affect the ground-water flow. In the northeastern part of the basin, the units are not as thick as they are in the southwestern part of the basin because of shallower bedrock. Ground-water flow in the northeastern part of the basin is controlled by the location of the contact between the lower unit and bedrock. In the southwestern part of the basin, ground-water flow is influenced mainly by the finer-grained deposits (Brown and Pool, 1989).

\section{GENERAL GEOGRAPHIC INFORMATION SYSTEM DATA-CONVERSION METHODS}

To determine the basin-fill unit in which each well is completed, a GIS was used to create three-dimensional surfaces of the base of each aquifer unit. The series of steps within the GIS involve the creation of a number of spatially descriptive products (fig. 2). The GIS was used to create a product that is an expansion of the geohydrologic information provided by the original contour lines developed by Brown and Pool (1989). The first step was to digitize the contour lines for each unit. The resulting altitude and depth data were retained in a relational data base. Data for each unit were a separate data set, or coverage. The areas between the digitized contour lines within a coverage were interpolated by the use of triangulated irregular network (TIN) generation. (Words that appear in a hold font are defined in the "Definition of Terms").

A TIN surface is composed of nodes, edges, nonoverlapping triangles, and a hull. The complete TIN, therefore, can describe a surface profile. The TIN's were useful in creating cross sections and for error checking. 
Table 1. Descriptions and ranges in altitude of basin-fill units

[Data from Brown and Pool (1989)]

\begin{tabular}{|c|c|}
\hline Basin-fill unit & Lithologic description and range in altitude \\
\hline \multicolumn{2}{|r|}{ Upper unit } \\
\hline $\begin{array}{l}\text { Quaternary sediments } \\
\left(Q_{s}\right)\end{array}$ & $\begin{array}{l}\text { The upper unit is mostly consolidated silt, sand, and gravel. Thickness varies from } 61 \text { meters or } \\
\text { less near basin margins to } 122 \text { meters near the confluence of the Gila and Salt Rivers. Altitude } \\
\text { ranges from } 183 \text { to } 396 \text { meters above sea level. }\end{array}$ \\
\hline \multicolumn{2}{|r|}{ MIddle unit } \\
\hline $\begin{array}{l}\text { Quaternary-Tertiary } \\
\text { sediments }\left(Q_{T S}\right)\end{array}$ & $\begin{array}{l}\text { The middle unit is a major water-bearing unit and consists of weakly consolidated clay, silt, sand, } \\
\text { and gravel and moderately to well-cemented siltstone in some places. This layer is as murh as } 245 \\
\text { meters thick and is the thinner of the two main water-bearing units. Altitude ranges fro } 7152 \text { to } \\
305 \text { meters above sea level. }\end{array}$ \\
\hline \multicolumn{2}{|r|}{ Lower unit } \\
\hline $\begin{array}{l}\text { Tertiary sediments } \\
\text { upper part }\left(T_{s u}\right)\end{array}$ & $\begin{array}{l}\text { The upper part of the lower unit is a major water-bearing unit, is mostly fine grained and consists } \\
\text { of weak to moderately cemented clay, silt, mudstone, gypsiferous mudstone, gypsum, and } \\
\text { interbedded sand and gravel. This unit is as much as } 300 \text { meters thick, in places, and is absent } \\
\text { along the mountain fronts in some areas. Altitude ranges from } 152 \text { meters below sea level to } 305 \\
\text { meters above sea level. }\end{array}$ \\
\hline $\begin{array}{l}\text { Tertiary sediments } \\
\text { lower part }\left(T_{s l}\right)\end{array}$ & $\begin{array}{l}\text { The lower part of the lower unit is mostly fine grained and consists of moderately to } \\
\text { well-cemented mudstone and siltstone, sand, gravel, and conglomerate. The lower part also } \\
\text { contains massive deposits of gypsum, anhydrite, halite, and includes basalt flows. Deposits } \\
\text { generally are fine grained in the graben and become increasingly coarser toward the basin margins. } \\
\text { The thickness of the lower part ranges from } 300 \text { meters near the basin margins to more th an } 3,050 \\
\text { meters thick in the graben. Altitude ranges from }-416 \text { to } 331 \text { meters. }\end{array}$ \\
\hline
\end{tabular}

A lattice for each basin-fill unit was created from the TIN's. These raster-data sets were needed to complete a GIS process called a lattice cell-value query, in which each basin-fill unit lattice is georeferenced over the lower basin-fill unit lattices, the well coverage is registered over the lattice stack, and the unit is determined for each well. Each well coverage included land-use and population-density data.

Lattices resulting from the TIN's were smoother than lattices resulting from a direct coverage-to-lattice conversion. The smoother lattices were considered more desirable because they are a closer approximation of the actual shape of an aquifer unit. An Arc Macro Language (AML) program (aqalt.aml; Supplemental Data, Part A) was run to speed the lattice cell-value query process. The TIN's were used before this process for error checking, to create cross sections for this report, and for possible future volumedetermination needs.

\section{LINE- AND LATTICE-DATA PREPROCESSING}

Determining the basin-fill unit in which a well is completed required collecting data on well depths and locations and generating data sets for the land surface and the basin-fill unit surfaces. In order to describe the horizontal aspects of the surfaces of the aquifer units as well as how the surfaces relate to each other vertically, the land surface and basin-fill unit altitude surfaces had to be defined and the well depths converted to altitudes in order to relate them to the altitudes of the land surface and basin-fill units.

In general, the types of GIS data sets necessary for the generation of surfaces are TII' 's and lattices. In order to generate TIN's and lat ices for the basin-fill unit layers, the data form of isolines on paper maps were digitized, and each iso'ine was given a $z$ value of altitude. To make commarisons between each layer, as would be done with a lattice cell-value query or a surface profile, each line coverage was converted to the same units with the same origin. The land surface was already in lattice 
LAND SURFACE

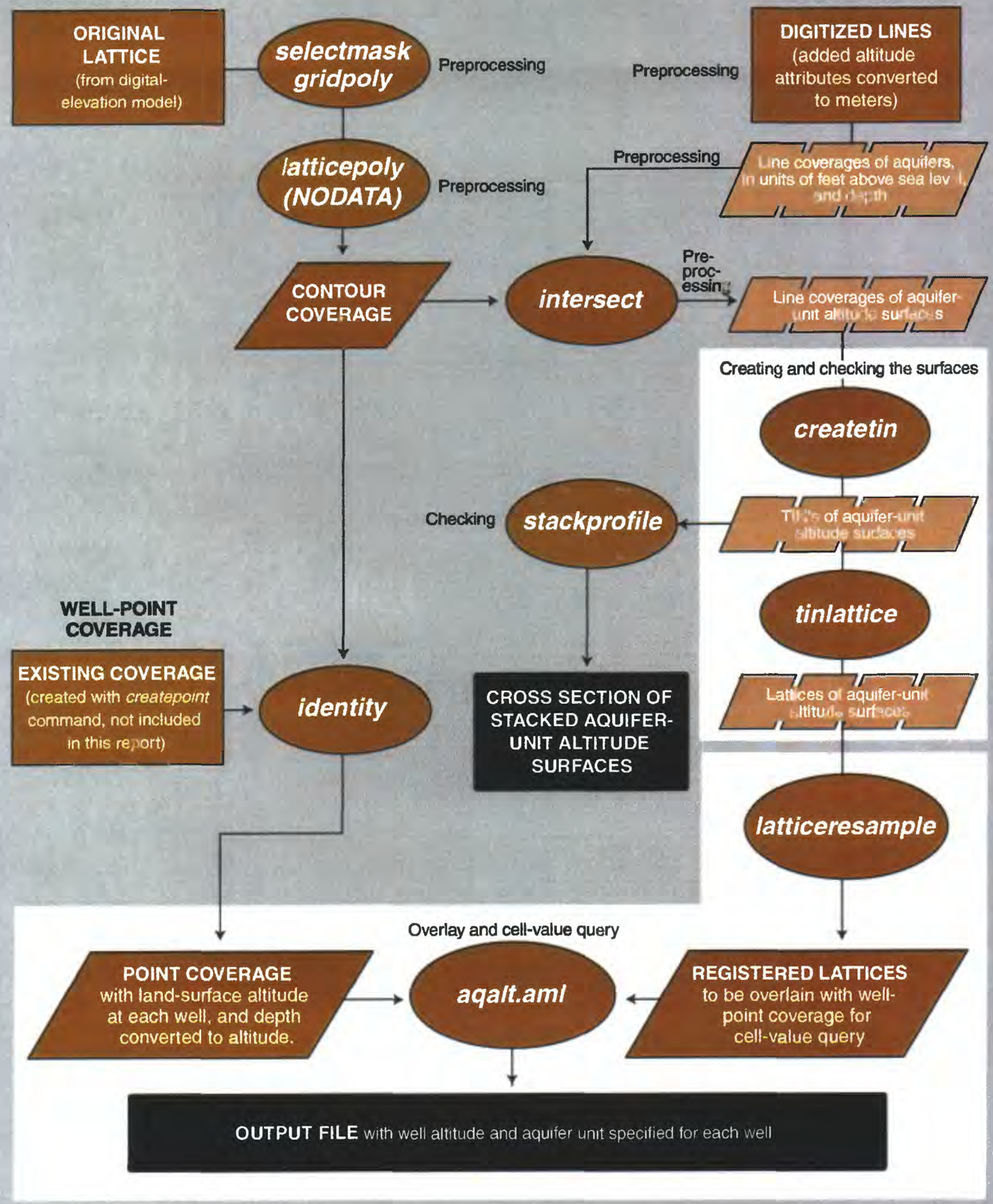

Figure 2. Flow chart of geographic information system commands. 
form, created from digital elevation model (DEM) files, and contained the altitude data in meters. Well-depth data, in feet below land surface, were converted to altitude data in meters using the land-surface altitude at the well.

\section{Land-Surface Altitude}

For the preparation of the land-surface GIS layer, a lattice was created by merging 1:250,000-scale DEM's, and clipping the lattice to the extent of the study area. Clipping to only the area of interest reduced the processing time and provided a better product for display (fig. 3). The clipped lattice was converted into a polygon coverage and retained the altitude values of the lattice. The polygon coverage of the land surface was used to convert depth data to altitude data for the one basin-fill unit that was lacking altitude values.

In this report, the following italicized words are the specific GIS commands. The next six commands were used to develop a lattice of the land surface for the WSRV detailing the general concept outlined above. Explanations are provided and generalized product names are used throughout the report to assist with GIS-product flow.

wsrv_dem = selectmask (grdalb, wsrvmask):

This step clipped the mosaiced grid, grdalb, using a "flat" lattice (no altitude values) of the boundary of the WSRV, masking out all of the regional lattice except the area of interest to present a lattice for only the WSRV. The resultant clipped lattice, wsrv_dem, has a value-attribute table (.VAT) that contains the altitude values in meters of each cell within the lattice. Resolution of the lattice is $90 \mathrm{~m}$ as was the original grid, grdalb.

wsrv_con $=$ gridpoly $\left(w s r v \_d e m, 80\right):$ The clipped lattice, wsrv_dem, was converted into a polygon coverage, wsrv_con, having a weed tolerance of $80 \mathrm{~m}$. A weed tolerance is used to generalize the complex surface polygon lines and remove any extraneous points that add no new information to the shape of the contour. The data included with this coverage are altitude in meters (GRID-CODE). When converting from a lattice (a series of cells), to a polygon coverage, the bourdaries of the polygon are determined by the borders of zones of cells having the same value (Environmental Systems Research Institute, 1994). The complexity of the land-surface altitude lattice, wsrv_dem, required that the vertices of lines that defined the polygons be at least $80 \mathrm{~m}$ apart. This generalized the lines and cecreased the size of the coverages. A weed tolerance equal to the same resolution of the lattice used to create the polygon coverage $(90 \mathrm{~m})$ was not used because it would have resulted in square polygons for single-cell zones.

clean wsrv_con wsrv_cocl: The polygon coverage created from the complex land-surface lattice, wsrv_con, was edited, and geometric errors were corrected in the clean coverage, wsrv_cocl. Polygon topology then was created for the cleaned coverage. Fuzzy tolerance, or the tendency for a line to alter its position within the set tolerances, was kept small by designating a double precision for the entire coverage processing. The clean process vas used throughout the data preprocessirg for all coverages. This process is noted 1 re only for completeness of documentation.

additem wsrv_cocl.pat wsrv_cocl.pat SURF.FEET $48 \mathrm{~B}$ : The polygon attribute table (.PAT) file for the land-surface coverage contained data in the item GRID-CODE from the lattice, which were the values of altitude in meters. The attribute item SURF.FEET was added to the .PAT file using the additem command to include surface-altitude values in feet. Values of SURF.FEET would be stored in the .PAT using an input width of fo' 1 r binary digits and an output width of eight binary digits. The polygon coverage of the land-surface contours, wsrv_cocl, could now be used to determine the altitude values for the base of the lower basin-fill unit, which had only depth values. Altitude of the well equals the land-surface altitude value minus the depth value of the well. The additem process was used throughout 


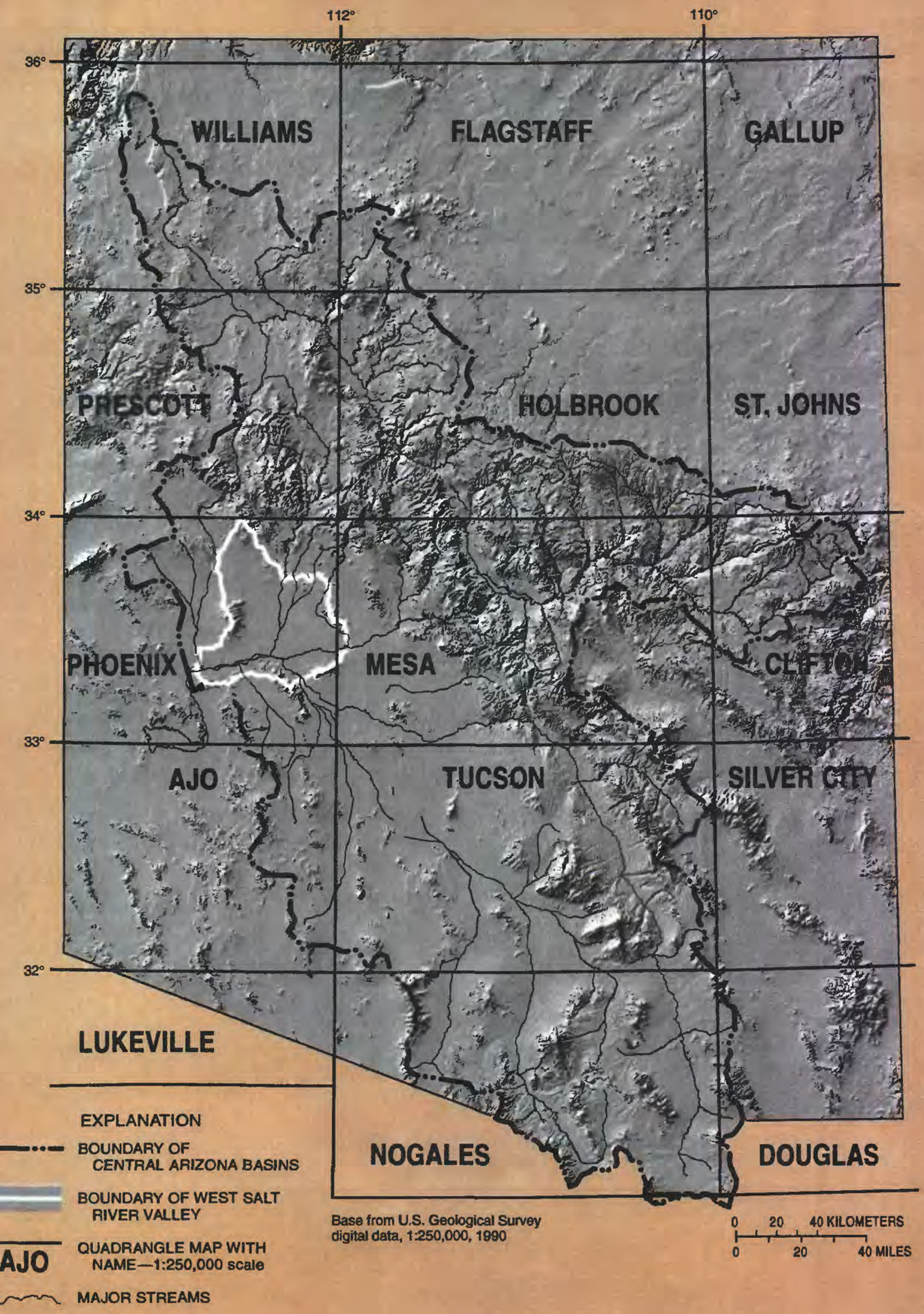

Figure 3. Shaded land surface generated from digital elevation model (DEM) files of 1:250,000-scale maps used to define land surface before cilpping to the extent of study area. 
the data preprocessing for all coverages and is noted here for completeness of documentation.

calc SURF.FEET = GRID-CODE *3.281: The attribute item SURF.FEET is populated with the calc command. Values were calculated by multiplying the GRIDCODE values by 3.281 to convert values of the surface altitude from meters to feet. The calc command was issued within Info, the data-base software used with Arc/Info, rather than at the Arc prompt, as with most commands detailed in this report. The calc command is used throughout the data preprocessing.

latticepoly wsrv_dem wsrv_surface_nodata nodata: The lattice used for the land surface, wsrv_dem, was checked for areas with missing values by converting the lattice to polygons and checking for any missing altitude values within the polygons. These polygons would be coded in the output coverage as having a DATA-CODE of -9999. Altitude values were complete in the data set for this report.

\section{Basin-Fill Unit Altitude Contours}

The best data source available to define the basin-fill unit altitude surfaces were contour lines from paper maps in Brown and Pool (1989, figs. 3, 7, 9, and 11). Brown and Pool developed the contour lines from data obtained from well drilling during 1983-85 and from drill cuttings and other lithologic data from more than 180 wells drilled over the last 40 years (James Brown, hydrologist, U.S. Geological Survey (USGS), oral commun., 1998).

The maps of the separate units contained the equal-altitude contour lines of the bases of the upper and middle units and the base of the upper part of the lower unit. Values for the base of the lower part of the lower unit were given as depth below land surface and not as altitude.

The initial product produced for processing the surfaces of the units were line coverages digitized from the contour lines (fig. 4). Each unit line was selected, and the altitude value, in feet, was added to a new attribute item, ALT. The attribute item for the metric equivalent, ALTMTR, was calculated for the contour lines. The International System of Units (SI units) were used because the large data set of the land surface created from the DEM's was in SI units. In order to convert the depth d ta of the lower part of the lower unit to altitude data, an intersect operation was performed as described below.

intersect wsrv__AquiferLayerName wsrv_cocl wsrv_AquiferLayerNameCo line: The altitude values in the land-surface coverage wsrv_cocl, in feet and meters, were added to each of the basin-fill unit coverages, wsrv_AquiferLayerName. An intersect function between coverages creates an output coverage containing the attributes of the line coverages and the polygon coverage within the extent of the polygon coverage. The wsrv_Aquifer LayerNameCo line coverages, therefore, contain the items of the land-surface pclygons (GRID-CODE, SURF.FEET) and the item attributes added to the line coverages of the basin-fill units (ALT, ALTMTR). The coverage of the lower part of the lower unit also had the item DEPTH, in feet.

To determine the altitude, ALT, for the base of the lower part of the lower unit, the DEPTH value was subtracted from the land-surface altitude value, SURF.FEET. The ALT values were multiplied by 0.3048 to get the altitude, in meters, for the ALTMTR item. Because the altitude values of a depth contour will change according to the corresponding land-surface altitude, the altitude calculation was performed at points where the land-surface contour lines crossed the basin-fill unit contour lines.

A limit line was defined where a contact between the middle unit and the upper part of the lower unit was not differentiated. This line was used as part of the outer extent of the coverage of the middle unit instead of using the boundaries of the ground-water subbasins within the mountain boundaries, and is indicated as the "line of differentiable middle unit" in figure 4. 

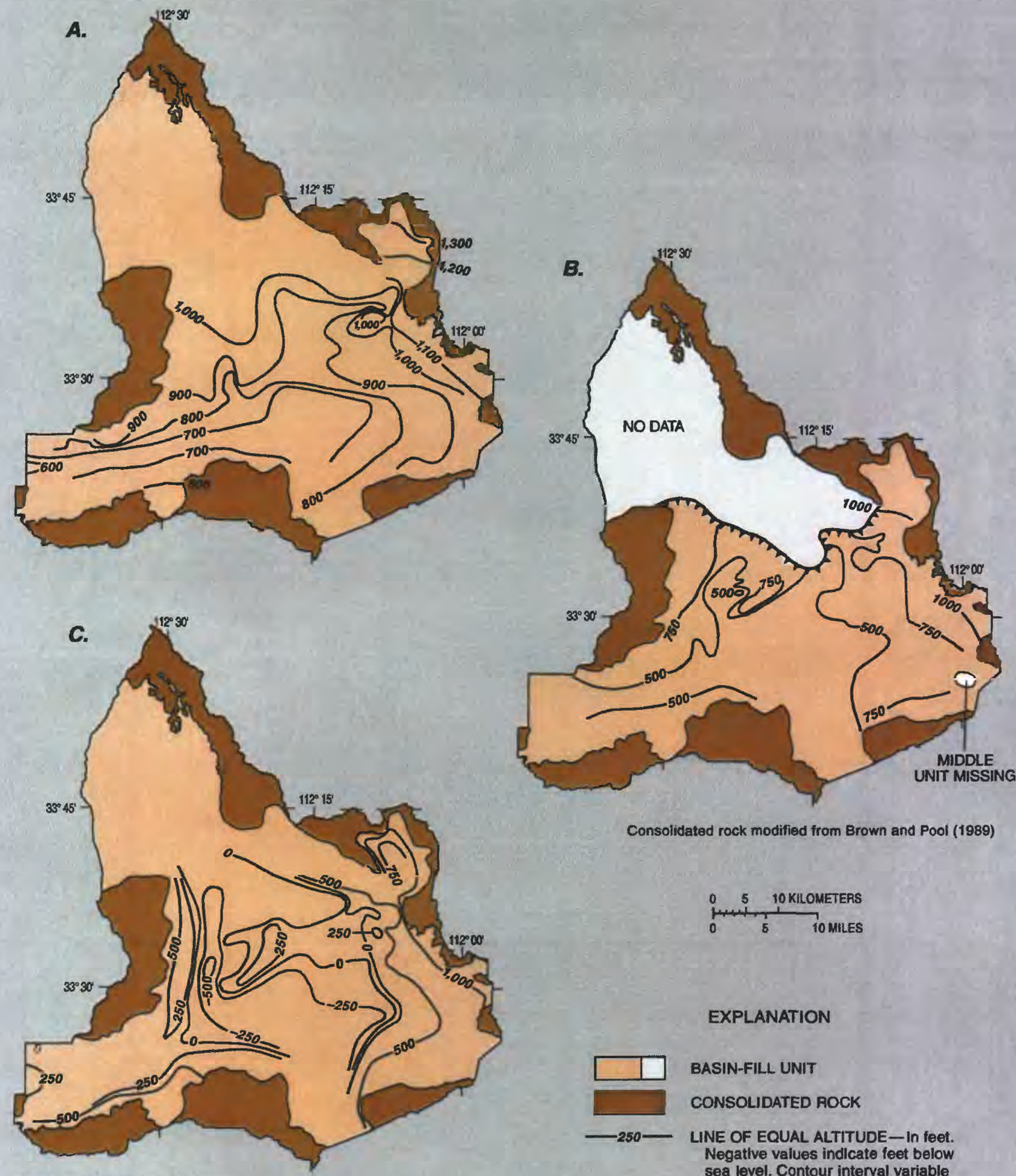

Consolidated rock modified from Brown and Pool (1989)

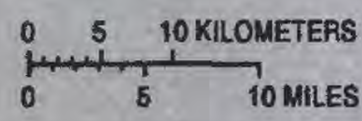

Base from U.S. Geological Survey digital data, 1:100,000, 1974

EXPLANATION

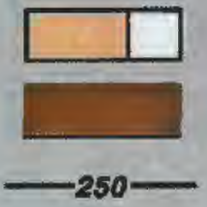

\section{BASIN-FILLL UNIT}

CONSOLIDATED ROCK

LINE OF EQUAL ALTITUDE- in feet. Negative values indlcate feet below sea level. Contour interval variable

TINE OF DIFFERENTIABLE MIDDLE UNIT

Figure 4. Approximate lines of equal altitude of the bases of the basin-fill units, west Salt River Valley. $A$, Base of the upper unit $\left(Q_{S}\right) . B$, Base of the middle unit $\left(Q_{T S}\right)$. C, Base of the upper part of the lower unit ( $T_{s u}$ ). Note: Contour lines were available only for approximate depth below land surface of the base of the lower part of the lower unit $\left(T_{s l}\right)$. 


\section{CREATING AND CHECKING THE SURFACES}

The vertical thickness of each basin-fill unit was determined by defining the altitude surfaces of the units. This information can be used to determine which unit intersects the perforated interval of a well.

Multiple-surface analysis operates in horizontal and vertical directions. In order for the final results of the analyses to make sense, the units of measure must be the same in all three directions. The preprocessing steps furnished polygon and arc coverages, which provide $x, y$, and $z$ coordinates in standard units of meters. The $z$ values are necessary for the next phase of surface development and creates the framework to allow for interpolation between known basin-fill unit surface points.

The land-surface data were in a usable form for overlay lattice cell-value query as a clipped lattice, wsrv_dem. The bases of the basin-fill units each had been digitized as line coverages with values of altitude above sea level added directly or calculated from depth below land surface. All altitude values were converted to meters and stored in the attribute item ALTMTR.

\section{Creating the Triangulated Irregular Networks}

The purpose of creating a TIN for the land surface and basin-fill unit surfaces is to interpolate spatial-data values for those areas between the contour lines thus creating a surface. The TIN's created from the lines represent only an interpolation between lines. A TIN minimizes that shortcoming somewhat by identifying, by way of "flat triangles," the location of conspicuous data gaps.

A TIN was created for the land surface and for the base of each basin-fill unit. The TIN creation involved using the line or polygon coverages of the preprocessing steps. The following createtin command and the two subcommands create a TIN from a coverage, wsrv_LayerNameCo, and confine the TIN's outer boundary to the outer extent of the coverage wsrv_clip.

createtin wsrv_LayerNameTIN (subcommand): cover wsrv_LayerNameCo line ALTMTR mass

(subcommand): cover wsrv_clip poly SPOT hardclip

In this instance, wsrv_LayerNameCo was a line coverage (fig. 4). The clip coverage, wsrv_clip, that was used to define the extent of the coverage was either the boundary of the consolidated rock, or in the case of the middle unit, the boundary of the middle unit as defined above. The item used to define the $z$ values was ALTMTR, which is the altitude above sea level in meters. The sources of the surface feature were the vertices of the lines of the digitized contours indicated by the word "mass" in the createtin command.

\section{Creating the Lattices}

Because they were from a sparse data set of contour lines, the resultant TIN's for the basin-fill units had areas where a lack of data resulted in "flat triangles." Additional data points in the form of well depth and lithologic contacts from well logs provided additional data for generating the base of the upper part of the lower unit (Brown and Pool, 1989; James G. Brown, hydrologist, USGS, oral commun., 1995).

Lattices were created from the TIN's of the basin-fill unit altitudes to equalize the "IN data into matrices. This procedure applied the surface interpolation from irregularly spaced nodes to evenly spaced matrices and is useful for continuous-data models such as surface interpolation. The land-surface lattice already existed as wsrv_dem, as discussed in the section entitled "Line- and Lattice-Data Preprosessing." The following tinlattice command and command options were used to generate the smoothest possible lattice having stable $x, y$, and $z$ coordinates.

tinlattice wsrv_LayerNameTIN wsrv_Layer NameLattice LINEAR 1: The command tinlattice converts a TIN, wsrv_Layer NameTIN, into a lattice and enters it in the command line as the output lattice, wsrv_LayerNameLattice, and allows a choice between two types of interpolators, 
quintic or linear, when equalizing the data from a TIN to a lattice. Ordinarily, when interpolating continuous-type data, such as a surface, it is possible to smooth the surface using a QUINTIC interpolator. In this model, however, the use of the QUINTIC interpolator produced pits and pyramid-like peaks along the outer boundary that were not in the original data. These pits and pyramid-like peaks are possible side effects of having no $H A R D$ breaklines in the data. A HARD breakline is a line having an enforced set of values, such as a stream; there is no interpolation across the line. The LINEAR interpolation option was used to avoid the creation of these artifact pits and peaks. The vertical multiplier, or $z$-factor, was set to 1 in the tinlattice command. This step was done to ensure explicitly that the horizontal units (meters) and the converted vertical units (meters) did not alter in the process. Hydrologic-modeling enhancements were not used on the lattices. The resolution of the isoline data was not fine enough in the study area for these enhancements.

\section{Aligning and Checking the Lattices}

Each basin-fill unit lattice is created with a default origin that would not necessarily be coincident with the default origins of the other basin-fill unit lattices. Although lattice alignment is not required for all lattice operations, it is needed for lattice operations concerning area and volume. Lattice alignment also was done to assist with the development of cross sections (described in the following section of this report). The outer $x-y$ extent of each lattice was defined in the lattice-creation process by the outer boundary (the mountains surrounding the WSRV, or the line of differentiable middle unit; fig. 4) and each unit altitude or converted-depth contour. Each basin-fill unit lattice had a different extent.

The possibility of nonalignment of the lattices was remedied by resampling each lattice. Initially, the projection data for each lattice had to be identified. The command projectcompare full ensured that all lattices had the same frojection information when using the command argument full. The projection definition file for all surfaces was as follows:

\begin{tabular}{|c|c|}
\hline PROJECTION & Albers \\
\hline UNITS & meters \\
\hline DATUM ..................... & 'NAD 1927 \\
\hline 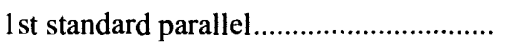 & 293000 \\
\hline 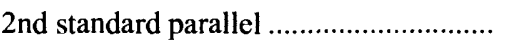 & 453000 \\
\hline Central meridian & -1113000 \\
\hline Latitude of projections origin ...................... & 230000 \\
\hline False easting, in meters & 0.0 \\
\hline False northing, in meters & 0.0 \\
\hline
\end{tabular}

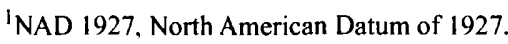

The reorientation of the origin and redefining the sample points of the lattices for the alignment process were done with the latticeresample command. The command also kept the $x-y$ coordinates within the same domain.

latticeresample wsrv_InLattice wsrv__Out Lattice 1: This command creates a new lattice, wsrv_OutLattice, from an existing lattice, wsrv_InLattice. Command-dialog prompts allow for reorienting the existing lattice by specifying the new origin $x-y$ points, the new $x-y$ maximum extents, and a new lattice resolution. As with the tinlattice command, a $z$-factor arg iment of 1 was used to keep the $x, y$, and $z$ values in meters.

The final dimensions of each lattice ar? shown below and are displayed using the command describelattice:

describelattice wsrv_OutLattice

Lattice description for wsrv_OutLattice Lattice size and origin

Points in $X / Y=23971789$

Origin $(x, y)=-115208.5101135027 .847$

Lattice distance between points

Distance $=30.000$

Lattice boundary

$X \min =-115208.510 \quad Y \min =113502.7 .847$

$X \max =-43328.510 \quad Y \max =1188667.847$ 
The origin is defined in meters for an Albers Equal-Area projection, the $x-y$ extents are in meters, as is the distance between sample points. The maximum and minimum $z$ values for altitude surface of each basin-fill unit will vary and also are in meters (fig. 5).

The lattice used for the land-surface altitude and the lattice used for each unit altitude were checked for polygons that have no data. Visual representation of a lattice is not sufficient to indicate if the related data table is empty and contains the NODATA value of -9999 . The -9999 value might be used numerically in any statistical or other mathematical process if not spotted and corrected. The command latticepoly, when used with the nodata option, creates coverages from a lattice, and assigns the NODATA value only to those polygons with no data values in the attribute tables.

latticepoly wsrv_InLattice wsrv_Out CoverageND nodata: The output coverage wsrv_OutCoverageND will assign a DATA-CODE of -9999 to any polygons that have no data. In this study, there were no empty polygons.

\section{EXAMINING THE BASIN IN CROSS SECTION}

A series of surfaces can be used to define the upper and lower extents of multiple volumes. Using a series of processes in the Arcplot command stackprofile, it is possible to "stack" each surface at the interpolated $z$ value, "cut" along a section through the multiple layers, and produce a cross section (fig. 6).

These processes can be used for data checking. As an example, an error was discovered in the generation of one layer using stackprofile. The line graphs created by stackprofile identified the anomaly of a lower unit crossing above an upper unit. Checking the minimum and maximum values of the ALTMTR item attribute of the coverage and the minimum and maximum of the $z$ values of the resultant TIN presented an arithmetic error, in which the feet-to-meters conversion process had been performed twice. This error was corrected by generating a new TIN for that layer.
The stackprofile command is actually a series of graphing and data-base file generation processes. In the paragraphs below, the purpose and final output of each option is explained.

stackprofile * Line_Cover Surface_File Profile_Info_file: Before running stackprofile, some preparatory items are required.

The Line_Cover is a coverage that prescribes the line segment used for defining the section through the layers (fig. 6). For the data set used in this study, a line was created from latitude and longitude data retrieved from well data to be used in the lattice overlay. The latitude and longitude data were projected to Albers Equal-Area meters using the Arc project file command and generated into a line coverage. Depth data were not added to the coverage.

The Surface file is a text file listing the TIN's for each layer in order from the surface to the lower part of the lower unit. The example below lists the lattice name, the sample distance, the graphing technique to be used, and the color of tle graph element.

lattice wsrv_Land SurfaceLattice 10 noshade 1

lattice wsrv_UpperLayerLattice 10 noshade 2

lattice wsrv_MiddleLayerLattice 10 noshade 3

lattice wsrv_UpperPartOfLowerLaverLattice 10 noshade 4

lattice wsrv_LowerPartOfLowerLayerLattice 10 noshade 5

Sample distance was $10 \mathrm{~m}$, although upon inspection of the results, $90 \mathrm{~m}$ wculd have given the same general results for that segment. Ten meters was selected as the closest distance between two poir's of the well coverage to be used in the overlay. The graphics in the plot from stackprofile were lines only; had no shading; and were in colors black, red, green, blue, and cyan.

The Profile_Info_file is a data-base file, in this case an Info file, where the results of 

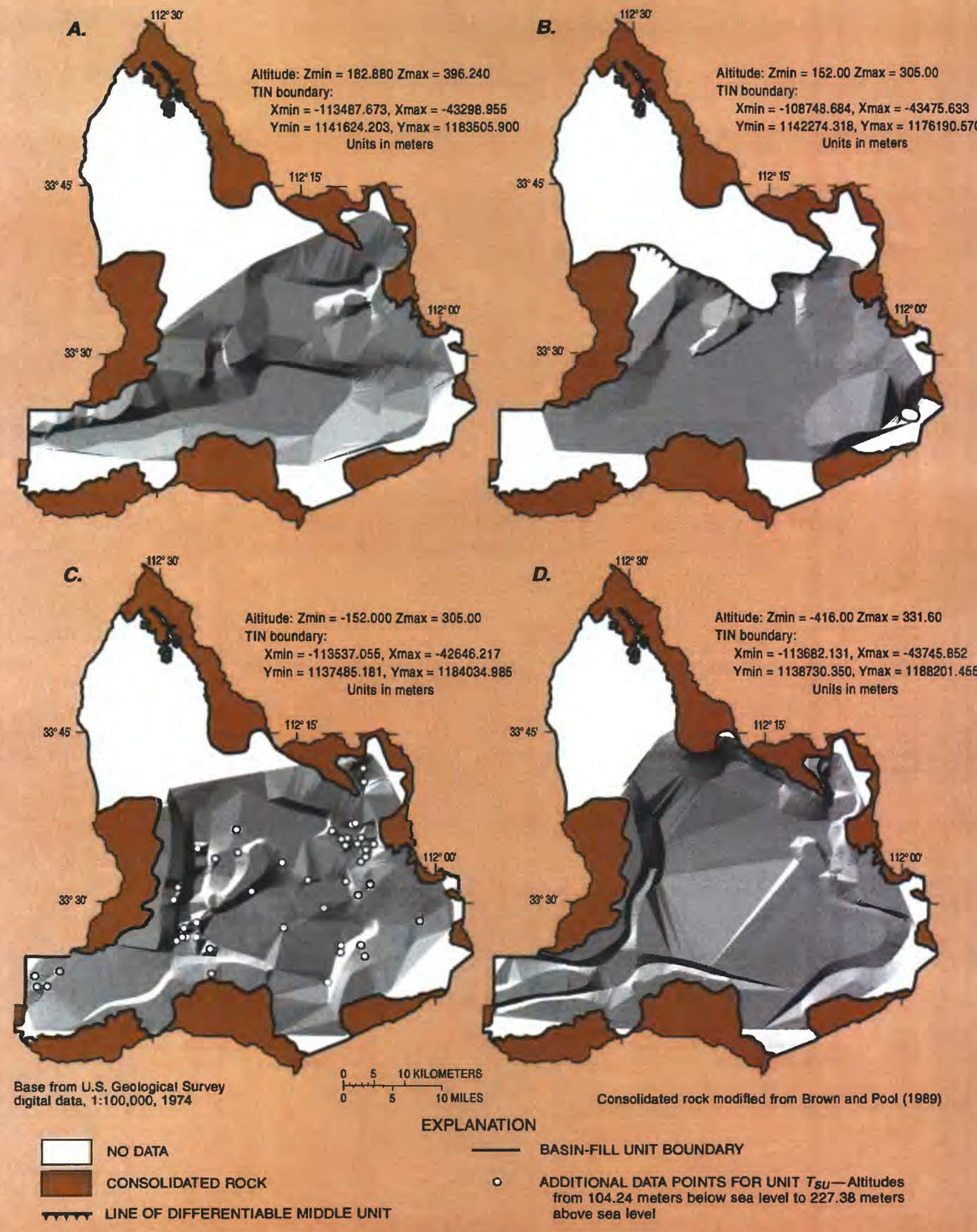

Figure 5. Surfaces generated by triangulated irregular network (TIN) for the four basin-fill units in the west Salt River Valley. A, Base of the upper unit $\left(Q_{S}\right)$. B, Base of the middle unit $\left(Q_{T S}\right)$. C, Base of the upper part of the lower unit $\left(T_{s u}\right)$. $D$, Base of the lower part of the lower unit $\left(T_{s l}\right)$. 


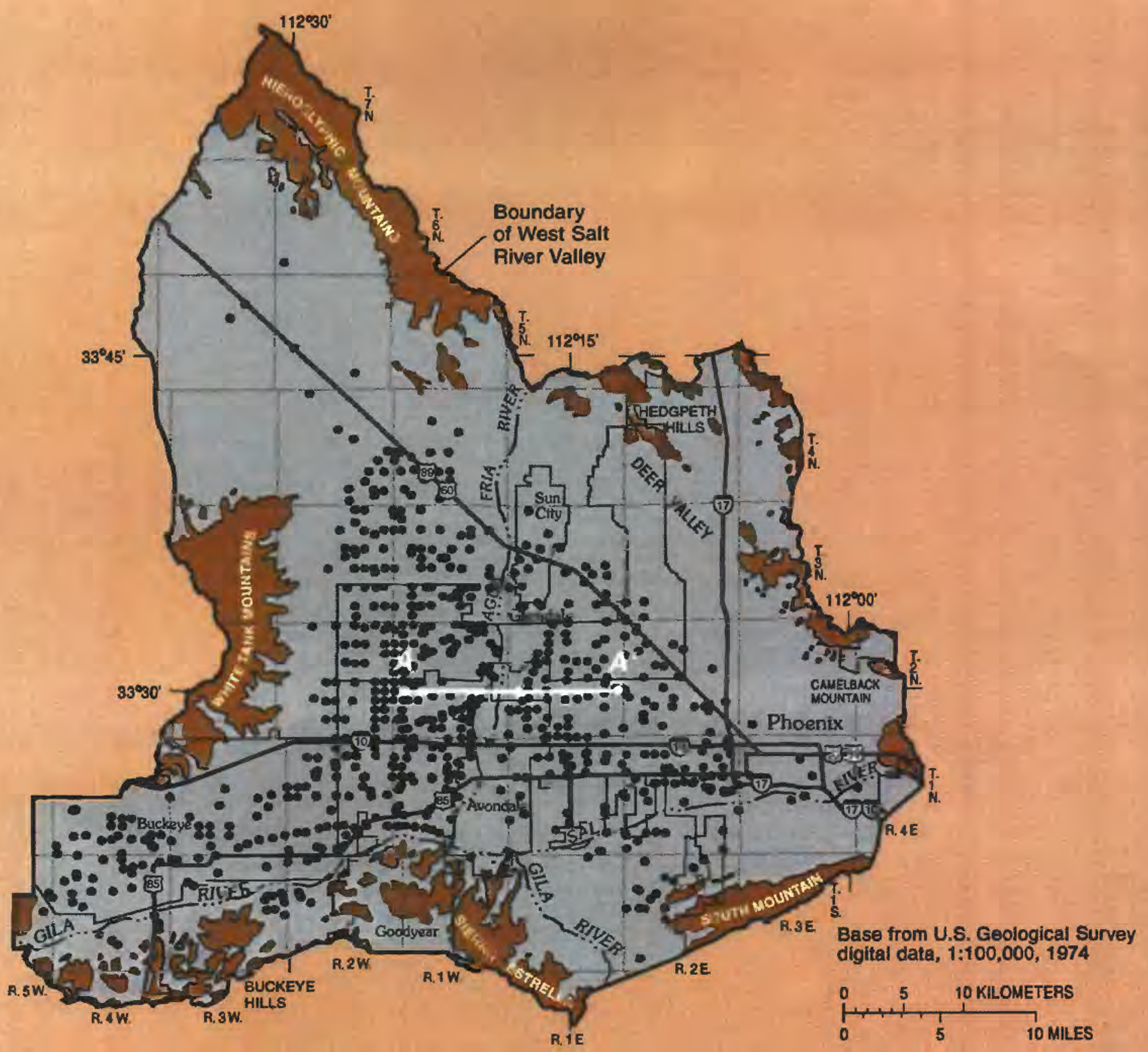

A

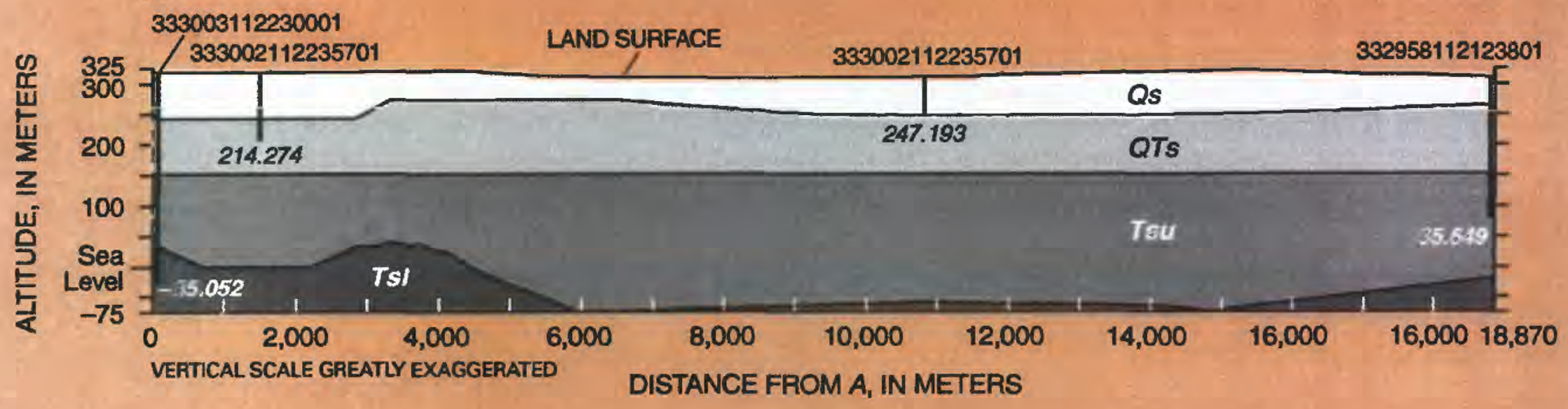

EXPLANATION

\section{SECTION}

$Q_{S}$ UPPER BASIN-FILL UNIT

QTS, MIDDLE BASIN-FILL UNIT

$T_{S U}$, UPPER PART OF LOWEA BASIN-FILL UNIT

$T_{S l}$, LOWER PART OF LOWER BASIN-FILL UNIT

MAP

ALLUVIAL DEPOSITS

\section{CONSOLIDATED} ROCK

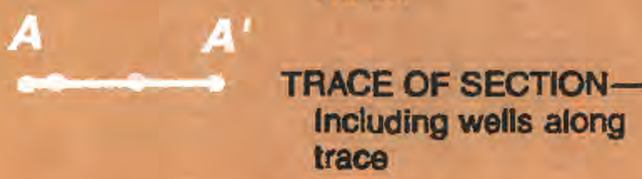

- WELl used by CENTRAL

ARIZONA BASINS

NATIONAL WATER-QUALITY

ASSESSMENT PROGRAM

333002112235701

WELL-Top number is site identiller.
Bottom number is altitude at base
of well, in meters

Figure 6. Wells, land surface, and bases of the upper and middle basin-fill units, and the base of the upper part of the lower unit. 
each tested sample point are stored. Stored data items are PX, the $x$ coordinate of the section-line sample point; PY, the corresponding $y$ coordinate; SECTION-ID and SURFACE-ID, which number the sections of the graph lines and define the surface from which the graph line is derived; DISTANCE, the distance from the origin of the line segment; and SPOT, the $z$ values at each sample point defined by DISTANCE. The graph lines formed by stackprofile using the above Surface file have many sample points because a sample is graphed every $10 \mathrm{~m}$ over a horizontal distance of more than $18,000 \mathrm{~m}$. The SPOT or altitude values over the line segment ranged from $234.27 \mathrm{~m}$ below sea level to $322.80 \mathrm{~m}$ above sea level for different altitude surfaces of the basin-fill unit.

\section{OVERLAY ANALYSIS WITH WELL- POINT DATA SETS}

Overlay techniques allow for many variously themed data sets to be compared and any relations to be examined. Data that are to be examined must be in a queriable form. For this report, altitudesurface data sets of the basin-fill units were overlain with well-location data sets and depth data sets in order to determine the unit within which the screened interval of a well is placed. Well-point coverages were generated from files that contained altitude data for each well. Well-location data, in the form of latitude and longitude, and depth data, in feet below land surface, were used to create a point coverage. The latitude, longitude, and screened interval were kept as item attributes.

In order to convert the depth values to altitude values, the altitude data for the land surface were added to the point-coverage data with the identity command in Arc.

identity wsrv_WellPointCov wsrv_cocl wsrv_WellPointAlt point: This command added the land-surface attributes SURF.FEET and GRID-CODE from the land-surface polygon coverage, wsrv_cocl, to the point coverage wsrv_WellPointCov. The new well-point coverage was named wsrv_WellPointAlt.
Using the additem and calc commands, two new items were added to the resultant coverage from the identity command, wsrv_WellPointAlt, that assisted with calculating the altitude of the depth of each well-WELLALT and WELLALTM.

calc WELLALT $=($ GRID-CODE *3.281) $-D E P T H:$ WELLALT was used to calculate the altitude of each well above sea level and keep the original units of feet.

calc WELLALTM =WELLALT *0.3048: The

WELLALT values were checked against values derived from SURF.FEET $-\mathrm{DEPTH}$.

\section{Lattice Cell-Value Query}

The concept behind a lattice cell-value query is to overlay the lattices of the land surface and the basin-fill unit surfaces with the well-point coverages. Each well has a unique identifier and an associated altitude in meters for the well bottom. Each lattice has altitude values associated with each 30-meter grid cell. As each well point is selected, the underlying basin-fill cells can be queried for the associated altitude values. These data were written to a file that was used to determine the basin-fill unit in which the well is completed. The unit is determined by comparing the altitude value for the bottom of the well to the altitude of the land surface or the base of exch unit.

To complete the lattice cell-value quory in a timely manner for the large numbers of wells in each well-point coverage, a process was developed to automate the query. The actual lattice cell-value query involves defining the extent of the area to be queried; listing the grids to be queried; selecting each well of each well-point coverage; completing the processes of retrieving the latitude and longitude data; converting those data into $x-y$ locations of a specific map projection, in meters; identifying that position in each basin-fill surface layer; querying each basin-fill unit grid for the altitude value; and saving the results. Although the lattice cell-value query part is handled easily with the cellvalue command in the GRID module of Arc/Info, the processes of converting a wall point into $x-y$ units is time consuming. 
The process to automate the lattice cell-value query included completing the well-point location conversion of depth below land surface to altitude above sea level, using the AML script (AQALT.AML; Supplemental Data, Part A), and saving the $x-y$ data in a file. The $x-y$ data were read into a GIS and used by the cellvalue command of the AML program.

Data were written from the point coverages with the form described for wsrv_WellPointAlt using Info. The commands used within Info are listed below.

\section{OUTPUT wsrv_WellPointAltOut.File}

\section{CALC \$COMMA-SWITCH $=-1$}

\section{PRINT STAID, LAT,LON,WELLALT,WELLALTM}

The output file, wsrv_WellPointAltOut.File, was a list of the unique identifier (STAID), latitude, longitude, and altitude of the bottom of the well in feet and meters.

The latitude and longitude of wsrv_Well PointAltOut.File were projected into $x-y$ units (meters with the Albers Equal-Area projection parameters used for the overlay process), and were added back into wsrv_WellPointAltOut.File that also contained the altitude of the bottom of each well. The file now contained the $x, y$, STAID, latitude, longitude, and well altitudes that were used by the AML. Three additional headings for the geologic designations of the basin-fill units also were used by the AML. These headings were Quaternary sediments $\left(Q_{s}\right)$, for the base of the upper unit; Quaternary-Tertiary sediments $\left(Q_{T s}\right)$, for the base of the middle unit; and Tertiary sediments $\left(T_{s u}\right)$, for the base of the upper part of the lower unit. Any well that extended below the base of the upper part of the lower unit was considered to be completed in the lower part of the lower unit. An example of part of an input file to the AQALT.AML is shown in table 2. The headings for the basin-fill units are in the file, but they are not filled in.

After the AML was run, output from the lattice cell-value query took the form of a file that includes the data from the input file and the altitude of each basin-fill unit below the well point. Table 3 is part of a sample of the output from the AQALT.AML. The altitudes for the basin-fill units are now filled in.

The output file was inspected for the basin-fill units that would bracket the value for WELLALTM, which is the altitude of tre bottom of the well, in meters. For example, well PV2E10N, whose base has an alt tude of $140.135 \mathrm{~m}$ above sea level, terminates in unit $T_{s u}$, which ranges from $75 \mathrm{~m}$ above sea level to $152 \mathrm{~m}$ above sea level.

The final files to be used by the NAWQA project staff would contain a column, UNIT, that lists the determined basin-fill unit for corresponding wells. Optionally, for future investigations, the UNIT information was added to the well-point coverage, wsrv_WellPointAlt, using Info ADD FILE techniques. Supplemental Data, Part B displays a part of one of the final files. In some instances when a well is in a position where the underlying basin-fill unit data do not exist, the output file of the lattice cell-value query will show only the altitude of the aquifer units that are present.

\section{EXAMPLE OF AN APPLICATICN OF DATA SETS}

The following is an example of a GIS application using the data sets for the basin-fill unit surface altitudes. No hydrologic or other interpretations are presented.

Data that describe land-use type and population density were added to each well in the point coverages using the identity commard.

identity wsrv_WellPointCov wsrv_LandUse wsrv_AltLu point: This command was used to add the land-surface attribute $\mathrm{LU}$ from a land-surface polygon coverage, wsrv_LandUse to the point coverage wsrv_WellPointCov. The new well-point coverage with the added land-use data was wsrv_AltLu. This coverage contains altitude data and land-use data for each well.

identity wsrv_AltLu wsrv_PopulationDensity wsrv_AltLuPop point: Population-density data were added to the new well-point coverage wsrv_AltLu. The data were stored 
Table 2. Example of an input file to AQALT.AML

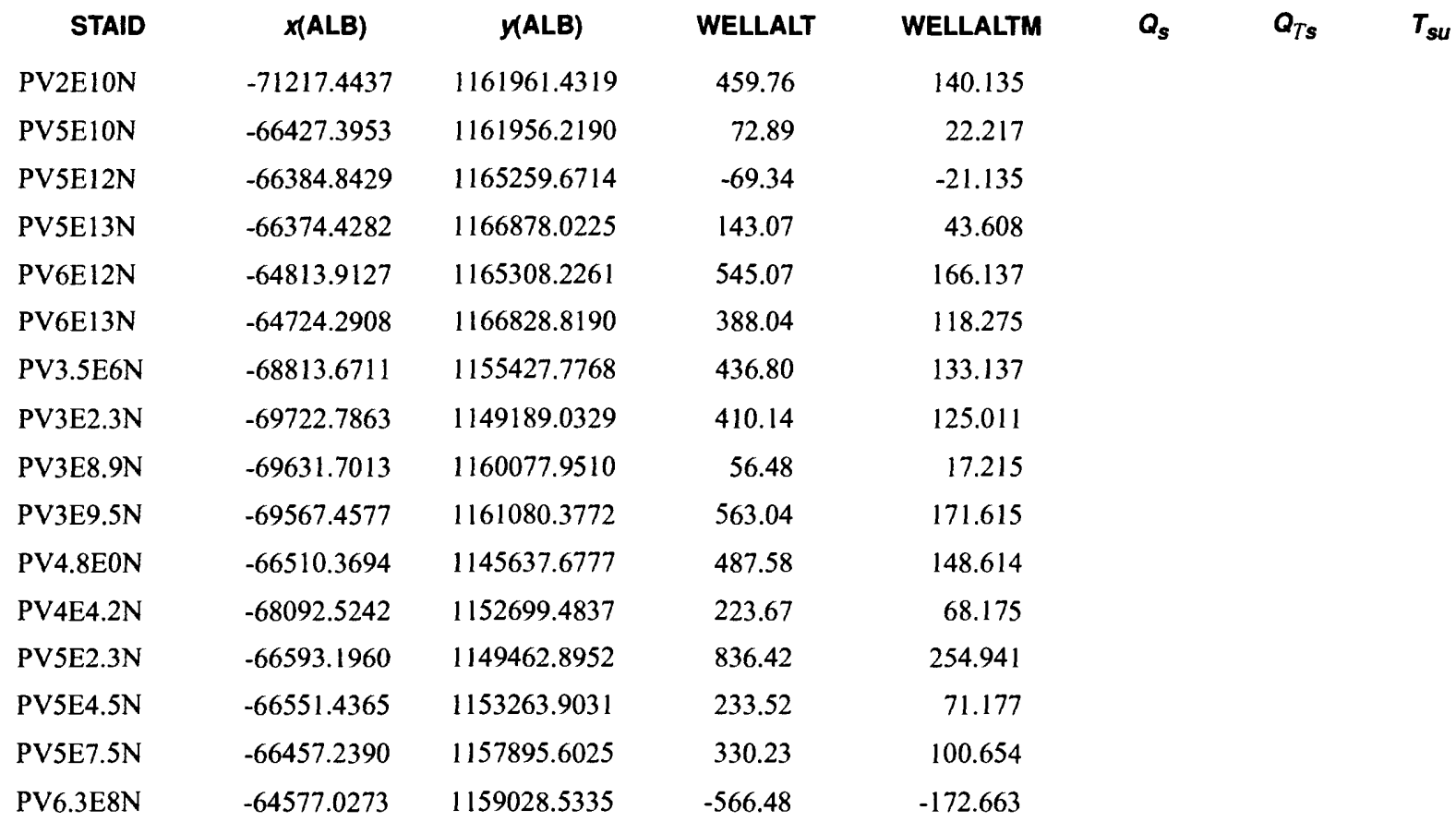

Table 3. Example of an output file from AQALT.AML

$\begin{array}{cccccccc}\text { STAID } & \text { X(ALB) } & \text { MALB) } & \text { WELLALT } & \text { WELLALTM } & Q_{\boldsymbol{s}} & \boldsymbol{Q}_{T s} & T_{s u} \\ \text { PV2E10N } & -71217.4437 & 1161961.4319 & 459.76 & 140.135 & 267.8552 & 152 & 75.0061 \\ \text { PV5E10N } & -66427.3953 & 1161956.2190 & 72.89 & 22.217 & 274.32 & 152 & -2.221749 \\ \text { PV5E12N } & -66384.8429 & 1165259.6714 & -69.34 & -21.135 & 274.32 & 152 & 18.66369 \\ \text { PV5E13N } & -66374.4282 & 1166878.0225 & 143.07 & 43.608 & 278.5574 & 152 & 0.765 \\ \text { PV6E12N } & -64813.9127 & 1165308.2261 & 545.07 & 166.137 & 286.0137 & 154.8 & 3.894699 \\ \text { PV6E13N } & -64724.2908 & 1166828.8190 & 388.04 & 118.275 & 297.3601 & 157.9 & 15.132 \\ \text { PV3.5E6N } & -68813.6711 & 1155427.7768 & 436.80 & 133.137 & 213.3 & 152 & -57.91989 \\ \text { PV3E2.3N } & -69722.7863 & 1149189.0329 & 410.14 & 125.011 & 213.36 & 152 & -23.82506 \\ \text { PV3E8.9N } & -69631.7013 & 1160077.9510 & 56.48 & 17.215 & 256.1445 & 152 & -77.13929 \\ \text { PV3E9.5N } & -69567.4577 & 1161080.3772 & 563.04 & 171.615 & 263.6405 & 152 & -53.57051 \\ \text { PV4.8E0N } & -66510.3694 & 1145637.6777 & 487.58 & 148.614 & 220.47 & 152 & -27.90115 \\ \text { PV4E4.2N } & -68092.5242 & 1152699.4837 & 223.67 & 68.175 & 213.36 & 152 & -45.18295 \\ \text { PV5E2.3N } & -66593.1960 & 1149462.8952 & 836.42 & 254.941 & 213.36 & 152 & -47.89269 \\ \text { PV5E4.5N } & -66551.4365 & 1153263.9031 & 233.52 & 71.177 & 213.36 & 152 & -67.19806 \\ \text { PV5E7.5N } & -66457.2390 & 1157895.6025 & 330.23 & 100.654 & 245.2339 & 152 & -49.24221 \\ \text { PV6.3E8N } & -64577.0273 & 1159028.5335 & -566.48 & -172.663 & 268.0153 & 152 & -10.23607\end{array}$


in the attribute item POPCLASS of the newly created coverage, wsrv_AltLuPop.

The point coverage from the above processes, wsrv_AltLuPop, was used to create an Info output file. The output file in this example contained a unique identifier (STAID), land-use data (LU), population-density data (POPCLASS), and well-depth data (DEPTH). Other headings included latitude and longitude, LATDEC and LONDEC.

AQALT.AML was run and the resulting file, welllupopgeo.rdb, is shown in Supplemental Data, Part B. The file lists the well identifier, the basin-fill unit, locational information, land use for areas surrounding each well, population density for areas surrounding each well, and the depth of each well. From this file, assessments can be made regarding well depth, basin-fill unit altitude, and possible land-use and population relations.

\section{METHODS FOR IMPROVEMENT}

The processes described in this report defined volumes for basin-fill units using bounding surfaces with Arc/Info version 7.0, that were meant to provide a first look at retrospective data. The following suggestions may improve the processes:

- Contour lines shown in the report by Brown and Pool (1989) were derived from point data (James G. Brown, hydrologist, USGS, written commun., 1995). Using the point data could provide additional altitude values that would result in a smoother final lattice.

- Maximizing the number of available data points from multiple, quality-assured sources before TIN creation would result in a smoother, more realistic, less stairstep-shaped product. Point data from additional published reports also could be used.

- The Arc/Info set of commands, topogrid, contains a series of hydrologically correct suppositions for grid-surface generation and could be used if information concerning ground-water movement in the aquifer was identified. Topogrid most likely would correct the step-like appearance of each basin-fill unit surface that resulted from using the techniques descriked in this report.

- ArcView module Spatial Analyst can be used to automate the processes used to generate the basin-fill unit altitude surfaces and the overlay processes.

- Automating the process of deciding which two basin-fill units bracket the bcttom of a well would increase the speed of determining the aquifer unit in which the well is completed. These steps could be added to the AML shown in Supplemental Data, Part A.

\section{SUMMARY}

The primary goal of this report was tc describe a technique to define the upper ard lower boundaries of the basin-fill units of the multilayered aquifer using a GIS to determine the aquifer unit in which a well was completed in the west Salt River Valley as part of the CAZB NAWQA program. The aquifer in the west Salt River Valley is divided into three hydrogeologic units - the upper, middle, and lower. $T$ e lower unit is subdivided into an upper and lower layer. Data necessary to complete the GIS procedures were the land-surface DEM files, lines of equal altitude for the basin-fill unit surfares, and well-location and well-depth data. Production of the altitude surfaces of the units required the creation of TIN's and lattices. Checking the lattices with the stackprofile command in Arc proved useful; however, an error of feet-to-meter conversion was found after inspecting the cross sections produced with that Arc/Info command.

Further uses by the CAZB included overlay analysis of the well-point coverage to include the altitude of the bases of the units and the overlying land use and population density. Final results were kept in file format to be used in relaticnal data bases and in coverages.

\section{SELECTED REFERENCES}

Arizona Department of Water Resources, 1997, Digital data of ground-water subbasin boundaries: Phoenix, Arizona Department of Water Resources, scale $1: 100,000$. 
Brown, J.G. and Pool, D.R., 1989, Hydrology of the western part of the Salt River Valley area, Maricopa County, Arizona: U.S. Geological Survey Water-Resources Investigations Report 88-4202, 5 sheets.

Cordy, G.E., 1994, National Water-Quality Assessment Program-Central Arizona Basins: U.S. Geological Survey Fact Sheet 94-016, 1 sheet.

Environmental Systems Research Institute, 1991a, Cell-based modeling with GRID: Redlands, California, Environmental Systems Research Institute, $327 \mathrm{p}$.

1991b, Surface modeling with TIN: Redlands, California, Environmental Systems Research Institute, $256 \mathrm{p}$.

1994, Arc/Info users guide, version 7.0: Redlands, California, Environmental Systems Research Institute, 7 volumes.
1996, Arc/Info On-line Help, version 5.1.1: Redlands, California, Environmental Systems Research Institute.

Freethey, G.W., Pool, D. R., Anderson, T. W., and Tucci, Patrick, 1986, Description and generalized distribution of aquifer materials in the alluvial basins of Arizona and adjacent parts of California and New Mexico: U.S. Geological Survey Hydrologic Atlas, HA-663, 4 sheets

Shafiqullah, Mohammed, Damon, P.E., Lynch, D.J., Reynolds, S.J., Rehrig, W.A., and Raymont, R.H., $1980, \mathrm{~K} / \mathrm{Ar}$ geochronology and geologic history of southwestern Arizona and adjacent areas: Tucson, Arizona Geological Digest, v. 12, p. 201-26?.

U.S. Geological Survey, 1987, National rapping program technical instructions-Digital elevation models: U.S. Geological Survey National Mapping Program, Technical Instructions, Data Users Guide 5, $38 \mathrm{p}$. 


\section{SUPPLEMENTAL DATA, PART A AQALT.AML}

The following is the AML program written to help automate the lattice cell-value query process. Pathnames are for the use of CAZB and can be replaced with local pathnames. 
* Platform: Unix

/* Language: AML

/* Version: 1

/* Arc Version: 7.0

/* Subsystem: AML run from Arc; uses GRID

/* Purpose: To perform lattice cell-value query operations of a specified stack of grids using an infile of selected well points. Program opens, writes, and closes the file containing the results of the lattice cell-value query.

/* Arguments:

/* Programs or menus called: None

/* Programs or menus called by: None 


\section{/* History:}

/* Author/Site, Date, Version

F

Julie A. H. Rees/USGS, Arizona, 22 August, 1995, Version 1

/* Disclaimer: Although this program has been used by the U.S. Geological Survey, no warranty, /* expressed or implied, is made by the USGS as to the accuracy and functionality of the program /* and related program material nor shall the fact of distribution constitute any such warranty, and /* no responsibility is assumed by the USGS in connection herewith.

/*
/*
/*

\&s grid $1=/$ azgis/jahr/gw2/aqalt/wsrv_bualat

\&s grid2 = /azgis/jahr/gw2/aqalt/wsrv_bmalat

\&s grid3 = /azgis/jahr/gw2/aqalt/wsrv_bulalat2

/*\&s grid4 = /azgis/jahr/gw2/aqalt/wsrv_blalat

\&term 9999

$\&$ s infile $=$ [getfile $/$ azgis $/ \mathrm{jahr} / \mathrm{gw} 2 / \mathrm{aqalt} /$ files $/ \mathrm{w}^{*}$-file -none -other 'Please select well location file'] $\&$ s outfile $=/$ azgis/jahr/gw2/aqalt/layers/[response 'Please name output file']

\&if [exists \%outfile\% -file] \&then

\&do

\&ty THIS FILE ALREADY EXISTS...

\&if [query 'Do you want to overwrite it' .true.] \&then

$\&$ s $\mathrm{xd}=[$ delete $\%$ outfile $\%$-file $]$

\&else

\&return

\&end

$/ * \quad$ open input $\&$ output files

\&s file $0=$ [open $\%$ infile $\%$ openstat 0 -read $]$ 
\&s file $1=[$ open $\%$ outfile $\%$ openstat $1-$ write $]$

/* read 1st line of input file (column headings)

/* and write to output file

$\&$ inline $=[$ read $\%$ file $0 \%$ rstat $]$

$\&$ s rite $=[$ write $\%$ file $1 \% \%$ inline $\%]$

/* check for current program and DISPLAY value

\&if [show program] ne GRID \& then

GRID

\&if [extract 1 [show display]] ne 9999 \& then

DISPLAY 9999

\&s mape $1=$ [getcover $\sim$ jahr/nawqa_shop/stds/gwpoly.dms/naw_* -polygon -other - none 'Please

select gw subbasin for map extent']

mape \%mape $1 \%$

$/^{*} \quad$ read 2 nd line of input file and start processing

$\& s$ inline $=[$ read $\%$ file $0 \%$ rstat $]$

\&do \&while $\%$ rstat $\%=0$

$\&$ s inline $=[$ trim $\%$ inline $\%-$ both $]$

\&s staid $=$ [before $\%$ inline $\%$ " "]

\&s templine $=[$ trim $[$ after \%inline\% " $]$-both $]$

\&s $\mathrm{x}=$ [before \%templine \% " ']

\&s templine $=[$ trim $[$ after \%templine \% " " $]$-both $]$

\&s y $=$ [before \%templine\% " ']

\&s templine $=[$ trim $[$ after \%templine \% " " $]$-both $]$

\&s alt $=[$ before $\%$ templine $\%$ " $]$

\&s cvl $=$ [show cellvalue \%grid $1 \% \%$ lon \% \%lat $\%$ ]

\&s cv2 $=$ [show cellvalue $\%$ grid $2 \% \%$ lon $\% \%$ lat $\%$ ]

\&s cv3 = [show cellvalue \%grid3\% \%lon\% \%lat $\%$ ]

$/ * \&$ s cv $4=$ [show cellvalue $\%$ grid $4 \% \%$ lon $\% \%$ lat $\%$ ]

\&s outline $=\%$ inline $\%$ ' ' $\%$ cv1\%' '\%cv2\%' '\%cv3\%

$\& s$ inline $=[$ read $\%$ file $0 \%$ rstat $]$

$\&$ s rite $=[$ write $\%$ file $1 \% \%$ outline $\%]$

\&end

$\&$ s close $=[$ close $\%$ file $0 \%]$

$\&$ s close $=[$ close $\%$ file $1 \%]$

\&ty \%outfile\% IS FINISHED...

\&return 


\section{SUPPLEMENTAL DATA, PART B}

Example of an RDB file converted from output of AQALT.AML

- page 29 follows 
Example of an RDB file converted from output of AQALT.AML

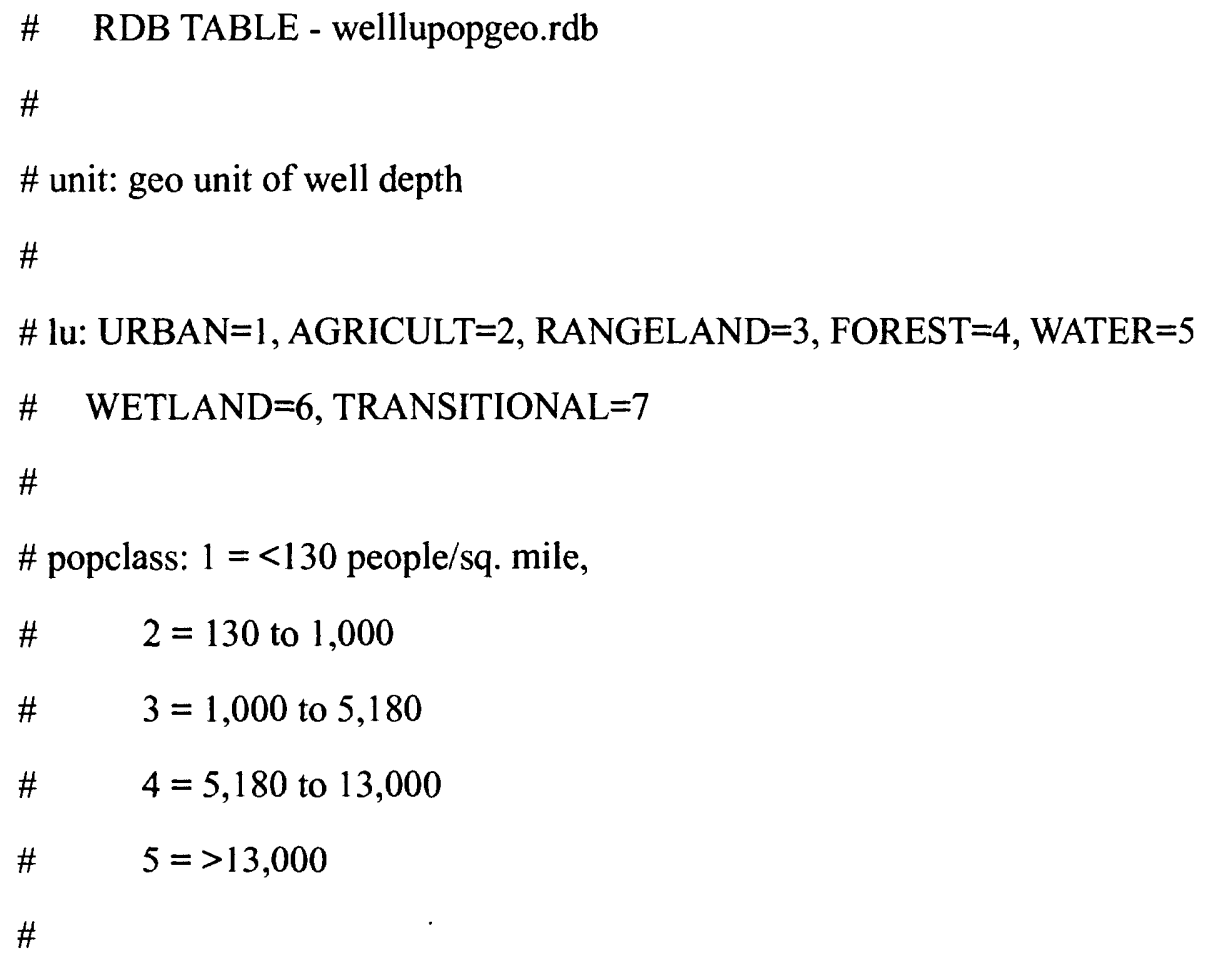

13

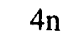

